\title{
Compositional and therapeutic properties of camel milk: A review
}

\author{
Ahmed R. A. Hammam* \\ Dairy and Food Science Department, South Dakota State University, Brookings 57007, SD, USA
}

\section{A B S T R A C T}

\begin{abstract}
Camel's milk is one of the most useful types of milk. Camel's milk is a white liquid, made up of a combination of emulsified fatty globules mixed with aqueous liquid. Several investigations have shown that camel's milk is able to treat many diseases even chronic diseases. It also proved that it contains a group of natural elements and compounds that have the special therapeutic ability in internal diseases. This work is aim to highlight and review the chemical composition of camel's milk and its therapeutic benefits, such as diabetes, diarrhea, food allergies, autism, cancer, chronic hepatitis, and cardiovascular diseases.
\end{abstract}

Keywords: Camel milk; Chemical composition; Therapeutic properties

\section{INTRODUCTION}

In addition to the importance of camels in the life of the desert and its population, camel's milk has been used since the ancient times in many therapeutic purposes in the population of the Middle East (Zibaee, 2015) and some areas of Asia and Africa (Gader and Alhaider, 2016). However, the science has taken into account the importance of this milk only in recent years, thus scientific research began studying the camel's milk and components, medicinal and therapeutic uses and effectiveness (Gader and Alhaider, 2016). It was found that camel's milk is the closest to the composition of mother's milk (Zibaee, 2015). Camel's proved to researchers that it serves as a gold mine for what can be obtained from health benefits (Gader and Alhaider, 2016), and in the study of camel's milk and its components and medicinal and therapeutic uses.

The camel's milk is a dark white color with a sweet smell and a sharp taste, and it can taste salty (Zibaee, 2015). The difference in the taste of camels' milk varies depending on the feed and the availability of drinking water for the camels. A layer of foam or butter appears when the milk is slightly agitated, and a lot of people could not taste the camel's milk because of its smell (Sisay and Awoke, 2015).
The composition of camel's milk is 3.1, 4.4, and $0.79 \%$ for protein, lactose, and minerals contents, respectively, and the total solids is $11.9 \%$, which are close to the ratio of total solids in breast milk (Zibaee, 2015). The moisture content is ranged from $84-90 \%$ in the camel's milk and this percentage varies according to the abundance of drinking water for the camels (Sisay and Awoke, 2015).

The therapeutic benefits of camel's milk are numerous, with having a role in autoimmune diseases, metabolic disorders, tuberculosis, hepatitis, cancer, rickets, diabetes, Crohn's disease, liver cirrhosis, autism, and rotavirus diarrhea (Zibaee, 2015).

\section{CAMEL'S MILK COMPOSITION}

The chemical composition of camel's milk is varied in different countries. The moisture, faKt, protein, lactose, and ash contents range from 85 to $90 \%, 2$ to $4.5 \%, 2.5$ to $4 \%, 4$ to $6 \%$, and 0.7 to $1.5 \%$, respectively. Camel's milk contains a maximum amount of vitamin $\mathrm{C}$ equivalent to three times that of dairy cows. The percentage of casein $70 \%$ of the protein in camel's milk (Farah and Ruegg, 1989; Haug et al., 2007; Wernery, 2007) compared to $80 \%$ casein of protein in cow's milk (Hammam et al., 2017; Hammam and Metzger, 2018). The fat in camel's milk is lower than

\footnotetext{
*Corresponding author:

Ahmed R. A. Hammam, Dairy and Food Science Department, South Dakota State University, Brookings 57007, SD, USA.

Tel.: 605-592-6864, E-mail: Ahmed.Hammam@sdstate.edu
} 
in cow's milk, and it is a smaller globule that can be easily absorbed and digested (Farah and Ruegg, 1989; Wernery, 2007). Camel's milk contains a high percentage of water ranging from $84 \%$ to $91 \%$ (Farah and Ruegg, 1989; Sisay and Awoke, 2015), which is not found in any other type of milk. The percentage of water in camel's milk could be different depending on the conditions that surround the camels (such as temperature and feed).

The camel's milk retains its quality for 12 days at $2^{\circ} \mathrm{C}$ while cow's milk retains its properties for no more than two days at the same temperature. It has been reported that camel's milk is stable at room temperature for 8-10 h (Mal et al., 2006), and this due to the anti-microorganisms (e.g. lactoferrin, lysozyme, immunoglobulin) in the camel's milk (El-Agamy, 2007; Konuspayeva et al., 2007; Laleye et al., 2008). The pH of camel's milk is neutral, but it quickly becomes acidic if left for a long time. Its taste varies from sweetness to salty. Camel's milk contains protein ranging from 2.5 to 4 percent, solids between 10 to 15 percent, fat between 2 to $4.2 \%$, lactose 3 to $6 \%$, sodium chloride 0.14 to $0.27 \%$, minerals (such as iron, calcium, and phosphorus), and vitamins (such as vitamins A, B, C, and D) (Almaw and Molla, 2000; Wernery, 2007).

\section{THERAPEUTIC USES OF CAMEL'S MILK}

Camel's milk has been found to contain iron more than $10 \%$ of milk in cow's and sheep. It also contains vitamins $\mathrm{A}, \mathrm{B}_{12}$ and $\mathrm{C}$. It also contains sodium, magnesium, and potassium. Camel's milk contains a small amount of fat, and here comes the first benefit for people with heart disease because fat is the most material cause problems of arteries, including strokes. It is important for the treatment diabetic due to its high proportion of insulin (Zagorski et al., 1998; El-Sayed et al., 2011; Malik et al., 2012; Shori, 2015; Mirmiran et al., 2017). Camel's milk is also useful for people with autism. Camel's milk does not cause any kind of allergies as in cow's milk, and it has benefits in strengthening the immune system, which reduces the proliferation of cancer cells (Noras, 2015; Zibaee, 2015).

\section{Camel's milk and diabetes}

Many studies have been announced that lactose intolerance or diabetes has been cured by using camel's milk (Agrawal et al., 2007; Al-Haj and Al-Kanhal, 2010; Malik et al., 2012). Human and animals experiments have found camel's milk is effective in controlling diabetes. The rate of diabetes among camel breeders in India who consume large amounts of camel's milk is zero $\%$ compared to $5.5 \%$ in other societies (Agrawal et al., 2011). The use of camel's milk by type one diabetics patients reduces their daily insulin requirements by $30-35 \%$ with low levels of blood sugar (Shori, 2015) and albumin protein in their urine, because camel's milk contains insulin, insulin-like proteins, immunoglobulins, and trace elements which have anti-inflammatory properties (Agrawal et al., 2011; El-Sayed et al., 2011; Gader and Alhaider, 2016).

Insulin in the camel's milk differs from human insulin and other animals by being surrounded by micelles, which protect it from digestion and degeneration at the top of the digestive system, making it easier to absorb and pass through to the blood (Abu-Lehia, 1989; Zagorski et al., 1998). Recent studies of diabetic experimental animals have found that they can prevent kidney damage associated with diabetes (Hamad et al., 2011; Shori, 2015; Kaskous, 2016). Antioxidants in camel's milk could also prevent symptoms of metabolic syndrome (such as elevated blood glucose and lipids), which may prevent pathological changes in the vessels that cause kidney and retina disease and complications in the cardiovascular system, and this, in turn, causes a large number of diabetes deaths (Gader and Alhaider, 2016).

The camel's milk is suitable for people with lactose intolerance who show symptoms of bovine milk due to the low lactose content in camel's milk as compared to cow's milk (Cardoso et al., 2010; Mullaicharam, 2014; Baubekova et al., 2015; Zibaee, 2015). The applications of camel's milk as diabetes treatment should be examined more to confirm its effectiveness.

\section{Camel's milk and diarrhea}

A study has been found that fermented camel's milk contains higher amounts of sodium and potassium which led to reduce diarrhea in rats and improve the symptoms of diarrhea in Crohn's disease and autism (Zibaee, 2015). Camel's milk has bioactive peptides, such as lactoferrin, lactoperoxidase, lysozyme, immunoglobulin, and peptidoglycan (El-Agamy et al., 1992; Kappeler, 1998).

\section{Camel's milk and food allergies}

Many researchers have reported that camel's milk could cure children who have food allergic (Shabo et al., 2005; El-Agamy et al., 2009; Al-Hammadi et al., 2010). Many studies have found that camel's milk does not cause the immune reactions or allergy caused by cow's milk (ElAgamy et al., 2009; Zibaee, 2015). This makes it suitable for the production of formula milk for infant formula, especially for children with this allergy. Many experiments have been investigated the food allergic children (Shabo et al., 2005). They found that immunoglobulin is responsible for the reduction of allergy symptoms when children consumed camel's milk for two weeks. As a result, the digestion ability of these children has improved. The researchers found that the difference in camel's milk protein 
from cow's milk protein was the cause of children's ability to tolerate it despite their susceptibility to cow's milk. It was also found that camel's milk is better than goat's milk in bovine milk allergy. More scientific research should be conducted to confirm the efficiency of camel's milk in treating food allergy (Zibaee, 2015).

\section{Camel's milk and autism}

It has claimed that camel's milk could be used as a cure for autism (Adams, 2013; Al-Ayadhi and Elamin, 2013; Zibaee, 2015). In a previous study published in 2005, which examined the effect of replacing cow's milk with camel's milk in children and adults with autism. Camel's milk which was consumed by a 4 years old girl for 40 days, a 15 years old child of for 30 days and some adults at the age of 21 years for two weeks resulted in positive results about the symptoms of autism (Shabo et al., 2005; Yagil, 2013). Another study found that parents reported improvement in many autism symptoms in their children after ingestion of camel's milk, such as getting better sleep, improving their perception of the place, improving visual and language communication, and improving their digestive symptoms (Wernery et al., 2012; Al-Ayadhi and Elamin, 2013). In a study of 60 cases of autism at the age of 2-12 years, the effect of eating $500 \mathrm{ml}$ of bovine's milk twice daily was compared with the same amount of camel's milk for two weeks (Zibaee, 2015). The results showed an improvement in behavioral and cognitive tests and a decrease in oxidative stress in the body due to camel's milk (Zibaee, 2015). Positive effects of camel's milk were found in the report of the case of an autistic child who was given camel's milk at the age of 9 years, where the symptoms of this child were monitored for 6 years, which the symptoms continued to improve. The child did not improve when he stops drinking camel's and the improvement was back again after returning to drink the camel's milk (Adams, 2013).

\section{Camel's milk and cancer}

The camel's milk is used to inhibit some cases of cancer, such as lung, breast, and colon (Korashy et al., 2012; Habib et al., 2013). Some studies have found that camel's milk could prevent the formation of new blood vessels resulting from inflammation. It also has fatal effects on liver cancer cells by blocking the gene expression of one of the enzymes needed to activate carcinogens (Korashy et al., 2012). None of the compounds responsible for cancer resistance in the camel's milk has been identified to date. However, lactoferrin has been found to have significant effects (Habib et al., 2013). It has been shown to give cancer patients with chemotherapy better results than chemotherapy alone and has had inhibitory growth effects colon and rectum cancer in humans (Habib et al., 2013). In addition, it found to have toxic effects of cancer cells by preventing growth, reproduction, and stimulate death.
These studies need more scientific support to confirm the role of lactoferrin found in camel's milk in the fight against cancer (Gader and Alhaider, 2016).

\section{Camel's milk and chronic hepatitis}

Camel's milk has positive effects on chronic hepatitis (Sharmanov et al., 1982; Ohag et al., 1998; Maghraby et al., 2005; Redwan and Tabll, 2007; Gader and Alhaider, 2016). Camel's milk had antiviral effects and was found to improve biochemical and physical parameters in chronic active liver disease patients (Sharmanov et al., 1982). Lactoferrin extracted from camel's milk also had anti-hepatitis $\mathrm{C}$ effects, which were found to prevent it from entering the cells (Konuspayeva et al., 2007; Redwan and Tabll, 2007). It has also reported that camel's milk enhances the immune response of human which inhibit chronic hepatitis (Saltanat et al., 2009). Lactoferrin of camel's milk is more anti-viral than bovine lactoferrin and lactoferrin extracted from breast milk (Ohag et al., 1998; Gader and Alhaider, 2016).

\section{Camel's milk and immune system}

Camel's milk has been examined in a lot of experiments to enhance the immune system (El-Agamy et al., 2009), and thereby, differentiating in the immunological similarities between camel's and cow's milk. The sequence of the protein in camel's milk differs from the protein in cow's milk (El-Agamy et al., 2009). The immunoglobulin in camel's milk is similar compared to the human body but the concentration of immunoglobulin is higher in camel's milk (Mullaicharam, 2014). Camel's milk contains antioxidants (lactoferrin) that enhance the function of the immune system in the human body, thus effectively prevent the infection of various diseases (Conesa et al., 2008). Consequently, camel's milk is useful for those suffering from immune system disorders such as multiple sclerosis and Crohn's disease, so camel's milk is effectively treated the immune problems. However, there is no scientific evidence that camel's milk is effective in the treatment of autoimmune diseases.

\section{Other benefits of camel's milk}

Camel's milk also could be used to cure other diseases, such as cardiovascular diseases (Agrawal et al., 2009, 2011; Al-Hashem, 2009). It was found that camel's milk reduces the level of blood from fibrinogen in rats with diabetes, indicating the presence of preventive effects of camel's milk in cardiovascular diseases. In addition to the mentioned ability to prevent complications of diabetes affecting the cardiovascular system (Agrawal et al., 2009, 2011; Al-Hashem, 2009; Gader and Alhaider, 2016). Camel's milk is a good source of protein, calcium, phosphorus, vitamin C, and niacin (Zibaee, 2015). Camel's milk enhances the body's natural defense functions (Zibaee, 2015) and can play a role in resisting many bacteria and 
viruses (Gader and Alhaider, 2016). Lactoferrin extracted from camel's milk has antifungal effects in mice infected with the Schistosoma mansoni (Zibaee, 2015).

\section{CONCLUSIONS}

Camel's milk is a white liquid, made up of a combination of emulsified fatty globules mixed with aqueous liquid. Camel's milk is a popular food of the Bedouin population and one of the camel products used by Central Asian people since ancient times. Camel's milk contains many important nutrients for the health and integrity of the body. Camel's milk contains 5.8\% lactose, mineral, salts, unsaturated amino acids, enough linoleic fatty acid to feed the body, vitamin $C$, vitamin $B_{2}$, and $70 \%$ casein of protein content. It contains an adequate amount of antibacterial and antifungal substances, such as arginine, lysine, phenyl, anamin, albumin, globulin, puritans, calcium, and antioxidants. Camel's milk reduces blood sugar, therefore a successful treatment for diabetes because it reduces the need for insulin. It solves the problems of autism in children, enhances the immunity of the body, and fights the microbes that attack the human body because it contains many organic compounds and proteins. In addition, it is useful to cure hepatitis, addresses the allergy caused by some types of foods.

\section{REFERENCES}

Abu-Lehia, I. H. 1989. Physical and chemical characteristics of camel milkfat and its fractions. Food Chem. 34: 261-271.

Adams, C. M. 2013. Patient report: Autism spectrum disorder treated with camel milk. Glob. Adv. Health Med. 2: 78-80.

Agrawal, R. P., R. Dogra, N. Mohta and R. Tiwari. 2009. Beneficial effect of camel milk in diabetic nephropathy. Acta Biomed. 80: 131-134.

Agrawal, R. P., S. Budania, P. Sharma, R. Gupta, D. K. Kochar, R. B. Panwar and M. S. Sahani. 2007. Zero prevalence of diabetes in camel milk consuming raica community of NorthWest Rajasthan, India. Diabetes Res. Clin. Pract. 76: 290-296.

Agrawal, R. P., S. Jain, S. Shah, A. Chopra and V. Agarwal. 2011. Effect of camel milk on glycemic control and insulin requirement in patients with Type 1 diabetes: 2-years randomized controlled trial. Eur. J. Clin. Nutr. 65: 1048.

Al-Ayadhi, L. Y. and N. E. Elamin. 2013. Camel milk as a potential therapy as an antioxidant in autism spectrum disorder (ASD). Evid. Based Complement. Altern. Med. 2013: 602834.

Al-Haj, O. A. and H. A. Al-Kanhal. 2010. Compositional, technological and nutritional aspects of dromedary camel milk. Int. Dairy J. 20: 811-821.

Al-Hammadi, S., T. El-Hassan and L. Al-Reyami. 2010. Anaphylaxis to camel milk in an atopic child. Allergy. 65: 1623-1625.

Al-Hashem, F. H. 2009. Camel's milk alleviates oxidative stress and lipid peroxidation induced by chronic aluminum chloride exposure in rat's testes. Am. J. Appl. Sci. 6: 1868.

Almaw, G. and B. Molla. 2000. Prevalence and etiology of mastitis in camels (Camelus dromedarius) in Eastern Ethiopia. J. Camel Pract. Res. 7: 97-100.

Baubekova, A., A. Kalimbetova, S. Akhmetsadykova, G. Konuspayeva and B. Faye. 2015. Comparison of d and I-lactate content in cow and camel milk. Veterinaria. 42: 397-398.

Cardoso, R. R. A., R. Santos, C. R. A. Cardoso and M. O. Carvalho. 2010. Consumption of camel's milk by patients intolerant to lactose. A preliminary study. Rev. Alerg. Mex. 57: 26-32.

Conesa, C., L. Sánchez, C. Rota, M. D. Pérez, M. Calvo, S. Farnaud and R. W. Evans. 2008. Isolation of lactoferrin from milk of different species: Calorimetric and antimicrobial studies. Comp. Biochem. Physiol. B Biochem. Mol. Biol. 150: 131-139.

El-Agamy, E. I. 2007. The challenge of cow milk protein allergy. Small Rumin. Res. 68: 64-72.

El-Agamy, E. I., M. Nawar, S. M. Shamsia, S.Awad and G. F. W. Haenlein. 2009. Are camel milk proteins convenient to the nutrition of cow milk allergic children? Small Rumin. Res. 82: 1-6.

El-Agamy, E. I., R. Ruppanner, A. Ismail, C. P. Champagne and R. Assaf. 1992. Antibacterial and antiviral activity of camel milk protective proteins. J. Dairy Res. 59: 169.

El-Sayed, M. K., Z. Y. Al-Shoeibi, A. A. A. El-Ghany and Z. A. Atef. 2011. Effects of camels milk as a vehicle for insulin on glycaemic control and lipid profile in Type 1 diabetics. Am. J. Biochem. Biotechnol. 7: 179-189.

Farah, Z. and M. W. Ruegg. 1989. The size distribution of casein micelles in camel milk. Food Struct. 8: 6.

Gader, A. G. M. A. and A. A. Alhaider. 2016. The unique medicinal properties of camel products: A review of the scientific evidence. J. Taibah Univ. Med. Sci. 11: 98-103.

Habib, H. M., W. H. Ibrahim, R. Schneider-Stock and H. M. Hassan. 2013. Camel milk lactoferrin reduces the proliferation of colorectal cancer cells and exerts antioxidant and DNA damage inhibitory activities. Food Chem. 141: 148-152.

Hamad, E. M., E. A. Abdel-Rahim and E. A. Romeih. 2011. Beneficial effect of camel milk on liver and kidneys function in diabetic sprague-dawley rats. Int. J. Dairy Sci. 6: 190-197.

Hammam, A. R. A. and L. E. Metzger. 2018. Production and storage stability of liquid micellar casein concentrate. J. Dairy Sci. 101: 8.

Hammam, A. R. A., A. A. Tammam, Y. M. A. Elderwy and A. I. Hassan. 2017. Functional peptides in milk whey: An overview. Assiut J. Agric. Sci. 48: 77-91.

Haug, A., A. T. Høstmark and O. M. Harstad. 2007. Bovine milk in human nutrition-a review. Lipids Health Dis. 6: 25.

Kappeler, S. 1998. Compositional and Structural Analysis of Camel Milk Proteins with Emphasis on Protective Proteins. Dissertation.

Kaskous, S. 2016. Importance of camel milk for human health. Emirates J. Food Agric. 28: 158-163.

Konuspayeva, G., B. Faye, G. Loiseau and D. Levieux. 2007. Lactoferrin and immunoglobulin contents in camel's milk (Camelus bactrianus, Camelus dromedarius, and Hybrids) from Kazakhstan. J. Dairy Sci. 90: 38-46.

Korashy, H. M., Z. H. Maayah, A. R. Abd-Allah, A. O. S. El-Kadi and A. A. Alhaider. 2012. Camel milk triggers apoptotic signaling pathways in human hepatoma HepG2 and breast cancer MCF7 cell lines through transcriptional mechanism. Biomed. Res. Int. 2012: 593195.

Laleye, L. C., B. Jobe and A. A. H. Wasesa. 2008. Comparative study on heat stability and functionality of camel and bovine milk whey proteins. J. Dairy Sci. 91: 4527-4534.

Maghraby, A. S., M. A. Mohamed and A. M. Abdel-Salam. 2005. Anti-schistosomal activity of colostral and mature camel milk 
on schistosoma mansoni infected mice. Asia Pac. J. Clin. Nutr. 14: 432.

Mal, G., D. S. Sena, V. K. Jain and M. S. Sahani. 2006. Therapeutic value of camel milk as a nutritional supplement for multiple drug resistant (MDR) tuberculosis patients. Isr. J. Vet. Med. 61: 88.

Malik, A., A. Al-Senaidy, E. Skrzypczak-Jankun and J. Jankun. 2012. A study of the anti-diabetic agents of camel milk. Int. J. Mol. Med. 30: 585-592.

Mirmiran, P., H. S. Ejtahed, P. Angoorani, F. Eslami and F. Azizi. 2017. Camel milk has beneficial effects on diabetes mellitus: A systematic review. Int. J. Endocrinol. Metab. 15: e42150.

Mullaicharam, A. R. 2014. A review on medicinal properties of camel milk. World J. Pharm. Sci. 2: 237-242.

Noras, M. 2015. Nutritional and therapeutic characteristics of camel milk in children: A systematic review. Electron. Physician. 7(7): 1523-1528.

Ohag, H. M., A. Mohamed, O. K. Saeed, A. Elawad, S. Elsayed, S. Elhussein and G. Daffalla. 1998. Clinical trials for treatment of ascites with camel urine. J. Arab Board Health Specializations. 7: 25-29.

Redwan, E. M. and A. Tabll. 2007. Camel lactoferrin markedly inhibits hepatitis $C$ virus genotype 4 infection of human peripheral blood leukocytes. J. Immunoassay Immunochem. 28: 267-277.

Saltanat, H., H. Li, Y. Xu, J. Wang, F. Liu and X. H. Geng. 2009. The influences of camel milk on the immune response of chronic hepatitis $B$ patients. Xi bao yu fen zi mian yi xue za zhi= Chin. J. Cell. Mol. Immunol. 25: 431-433.

Shabo, Y., R. Barzel, M. Margoulis and R. Yagil. 2005. Camel milk for food allergies in children Isr. Med. Assoc. J. 7: 796.

Sharmanov, T. S. H., A. K. Zhangabylov and R. D. Zhaksylykova. 1982. Mechanism of the therapeutic action of whole mare's and camel's milk in chronic hepatitis. Vopr. Pitan. 1: 17-23.

Shori, A. B. 2015. Camel milk as a potential therapy for controlling diabetes and its complications: A review of in vivo studies. J. Food Drug Anal. 23: 609-618.

Sisay, F. and K. Awoke. 2015. Review on production, quality and use of camel milk in Ethiopia. J. Fish. Livest Prod. 3: 2.

Wernery, R., S. Joseph, B. Johnson, S. Jose, M. Tesfamariam, M. Ridao-Alonso and U. Wernery. 2012. Camel milk against autism-a preliminary report. J. Camel Pract. Res. 19: 143-147.

Wernery, U. 2007. Camel Milk-New Observations. In Proceedings of the International Camel Conference, p. 200-204.

Yagil, R. 2013. Camel milk and its unique anti-diarrheal properties. Isr. Med. Assoc. J. 15: 35-36.

Zagorski, O., A. Maman, A. Yaffe, A. Meisler, C. Van Creveld and R. Yagil. 1998. Insulin in milk-a comparative study. Int. J. Anim. Sci. 13: 241-244.

Zibaee, S. 2015. Nutritional and therapeutic characteristics of camel milk in children: A systematic review. Electron. Physician. 7: 1523. 